\section{O CUIDADO PRESTADO PELA ENFERMEIRA À PESSOA VIVENDO COM HIV NO BRASIL}

\section{CARE PROVIDED BY THE NURSE TO THE PERSON LIVING WITH HIV IN BRAZIL}

Cleuma Sueli Santos Suto ${ }^{1}$ / Eliana Maria de Carvalho ${ }^{1}$ /

Fabiane Silva Santos ${ }^{1} /$ Géssica Souza de Almeida ${ }^{1 /}$ José Andrade Almeida Junior ${ }^{1, *} /$ Ueliton Alves Vieira ${ }^{1}$

\section{INTRODUÇÃO}

A identificação do vírus da imunodeficiência humana (HIV) e da síndrome da imunodeficiência adquirida (AIDS) ocorreu há pouco mais de três décadas, porém, o número de pessoas infectadas e doentes tem aumentado rapidamente nesse curto período de tempo. Como afirmaram Gomes e Oliveira (2008), a AIDS é uma doença que tem trazido preocupações ao mundo inteiro diante das grandes responsabilidades de assistência e cuidados específicos que requerem a atenção tanto das pessoas acometidas, quanto daquelas envolvidas diretamente com o cuidado ao longo dos tempos, desde o seu surgimento, principalmente para aquelas que necessitam de cuidados nos serviços de saúde.

Desde o surgimento do HIV/AIDS, até os dias atuais, observou-se uma crescente evolução quanto ao tratamento e à detecção de casos da doença, fator que tem amenizado o sofrimento de pessoas acometidas e possibilitado uma maior expectativa de vida por detectar a infecção nos estágios iniciais e pela descoberta de drogas potentes contra o vírus.

${ }^{1}$ Departamento de Educação - Campus VII, Universidade do Estado da Bahia. Rodovia Lomanto Junior, BR 407, Km 127, s/n, Barbosa Santos, Senhor do Bonfim BA, CEP 48.970-000

E-mail para correspondência: andrade.junior320@gmail.com

Rev. ComCiência - dez. 2018, vol. 3, no. 3, p. 14-22 / doi: 10.36112/issn2595-1890.v3i1.p14-22 
De acordo com Brunner et al. (2008), mesmo tendo ocorrido grandes avanços para o tratamento de pessoas infectadas pelo HIV, a epidemia ainda é um sério problema de saúde pública nos Estados Unidos e no mundo.

A enfermeira, como membro da equipe multidisciplinar, desempenha um papel fundamental no cuidado à pessoa vivendo com o vírus da imunodeficiência humana $(\mathrm{PVH})$, minimizando o seu sofrimento e favorecendo uma melhor qualidade de vida para os mesmos e para os seus familiares.

Cuidado de Enfermagem é um fenômeno intencional, essencial à vida, que ocorre no encontro de seres humanos que interagem por meio de atitudes que envolvem consciência, zelo, solidariedade e amor (VALE; PEGLIUCA, 2011). Expressa um "saber-fazer" embasado na ciência, na arte, na ética e na estética, direcionado às necessidades do indivíduo, da família e da comunidade. Para Montezelli, Peres e Bernardino (2011), o cuidado é um complemento no processo do trabalho da enfermeira, uma vez que ela deve gerenciá-lo ultrapassando os métodos tecnicistas e visando à criatividade e à autonomia da enfermeira, sendo a base para as ações de Enfermagem para, assim, dispor de mudanças no modo de fazer gestão e nos modelos de cuidar.

A enfermeira, como integrante da equipe multidisciplinar, possui papel indispensável no cuidado de pacientes e familiares posto que a essência de sua prática profissional é o cuidado, o qual visa a promover conforto e suporte adequados. Nessa linha de pensamento, vale ressaltar a inserção da Enfermagem na assistência prestada à $\mathrm{PVH}$, predominantemente na importância dos diagnósticos e do planejamento das possíveis intervenções para um atendimento humaniza- do, integral, individualizado e regido pelos conhecimentos científicos, com ênfase na promoção, proteção, reabilitação e autocuidado (ROCHA et al., 2015).

Estudos sobre o conhecimento e a prática dos cuidados, particularmente na área de Enfermagem, no Brasil, atestam que são poucas as pesquisas que abordam a temática (SUTO; OLIVEIRA; PAIVA, 2018; ROCHA et al., 2015; CUNHA, 2014). Esse fato aponta a relevância de novos estudos que possam contribuir com a socialização de conhecimento acerca da importância do tema abordado. Ao considerar a importância do profissional de Enfermagem na prática dos cuidados e o quantitativo incipiente de estudos na literatura nacional, este estudo pretende ampliar e disseminar conhecimentos sobre essa temática direcionada para a pessoa vivendo com HIV.

Nessa perspectiva, o estudo teve, como fio condutor, a seguinte questão norteadora: Como a enfermeira participa do cuidado prestado à pessoa vivendo com o HIV? Assim, objetiva-se compreender o papel da enfermeira no cuidado prestado à pessoa vivendo com o HIV.

\section{METODOLOGIA}

Trata-se de um estudo exploratório, de revisão bibliográfica, com procedência científica. A revisão de literatura sobreleva a composição de uma contextualização para o problema e a análise das possibilidades presentes na literatura consultada para a concepção do referencial teórico do estudo (ALVES; MAZZOTTI, 2002).

Nesse tipo de estudo, o material reunido, por meio do levantamento bibliográfico, é disposto por procedên- cia. A análise do material permite a construção de ensaios que proporcionam a contextualização e a problematização e, por sua vez, uma primeira validação do quadro teórico a ser utilizado (VOSGERAU; ROMANOWSKI, 2014).

O estudo teve como objeto as produções científicas acerca do tema existentes em periódicos nas bases de dados Scientific Electronic Library Online - SciELO e Literatura LatinoAmericana e do Caribe em Ciências da Saúde - LILACS, no período de 2007 a 2017. As produções foram acessadas no dia $1^{\circ}$ de dezembro de 2017 , por quatro autores, que realizaram a etapa de seleção. A busca pela produção científica, publicada nos últimos dez anos, deu-se por se considerar o incremento da epidemia no início deste século, particularmente, em grupos populacionais de jovens e mulheres.

Na base de dados SciELO, fazendo o uso dos descritores HIV, Síndrome da Imunodeficiência Adquirida, cuidado e enfermeiro, utilizando o instrumento operacional booleano and, como primeiro resultado, foram encontrados dez artigos. Posteriormente, ao aplicar os filtros coleções, Brasil, artigos, idioma português, ano de publicação (recorte temporal dos anos 20072017), foram encontrados cinco artigos prontamente lidos. Apenas um dos artigos ajustou-se à proposta deste estudo.

Ao utilizar os mesmos descritores e sistema operacional, na base de dados LILACS, foram encontradas 38 publicações. Após a seleção com os filtros idioma português (33 artigos), ano de publicação para o recorte temporal entre 2007-2017 (30 artigos) e tipo de documento, restaram 22 artigos. Após a leitura de todos os resumos, oito artigos foram selecionados 
por se adequar à proposta desta pesquisa. Assim, nas duas bases utilizadas, nove artigos atenderam aos critérios de inclusão e exclusão previamente estabelecidos adequando-se ao propósito deste estudo.

Como critérios de inclusão, além do recorte de publicação entre 2007 a 2017 e do idioma português, elencaram-se artigos que relatam a convivência de pessoas com o HIV e/ou AIDS e a atuação do profissional de Enfermagem no cuidado ao paciente com HIV/AIDS, independente do sexo dos participantes. Quanto aos critérios de exclusão: artigos repetidos em ambas as bases de dados e que fugissem à temática proposta. A língua portuguesa foi necessária vez que o cuidado apresenta nuances locoregionais e a Política Nacional do Brasil de DST/AIDS se diferencia no contexto mundial.

No período utilizado para recorte, nos anos de 2007, 2008, 2012, 2013, 2016 e 2017 não se encontraram publicações evidenciando-se, assim, escassez de produção sobre o objeto estudado. Para o processo de análise, os artigos foram lidos na íntegra, por quatro dos autores, organizados em um quadro e analisados à luz da literatura vigente.

\section{RESULTADOS}

Para o detalhamento dos artigos, o quadro 1 foi organizado da seguinte forma: nome do autor, ano de publicação, título, tipo de estudo e os principais resultados obtidos. Os artigos foram organizados em ordem crescente de acordo o ano de publicação.

Quadro 1. Caracterização dos artigos analisados segundo o autor e o ano de publicação, o título, o tipo de estudo e os principais resultados, Senhor do Bonfim, 2018.

\begin{tabular}{|c|c|c|c|}
\hline $\begin{array}{l}\text { Autor, ano de } \\
\text { publicação. }\end{array}$ & Título & $\begin{array}{l}\text { Tipo de } \\
\text { estudo }\end{array}$ & Resultados \\
\hline $\begin{array}{l}\text { 1. GOMES, An- } \\
\text { tônio Marcos } \\
\text { Tosoli; CA- } \\
\text { BRAL Ivone } \\
\text { Evangelista. } \\
\text { 2009. }\end{array}$ & $\begin{array}{l}\text { O cuidado medi- } \\
\text { camentoso à crian- } \\
\text { ça com HIV: desa- } \\
\text { fios e dilemas de } \\
\text { familiares cuida- } \\
\text { dores }\end{array}$ & $\begin{array}{l}\text { Estudo } \\
\text { qualitativo }\end{array}$ & $\begin{array}{l}\text { O enfermeiro possui um importante papel na assistência a este } \\
\text { público englobando a prevenção de doenças oportunistas e a pro- } \\
\text { moção de sua saúde por meio, principalmente, da educação em } \\
\text { saúde. }\end{array}$ \\
\hline $\begin{array}{l}\text { 2. FORMOZO, } \\
\text { Gláucia Alexan- } \\
\text { dre; OLIVEIRA, } \\
\text { Denize Cristina } \\
\text { de. } 2010 .\end{array}$ & $\begin{array}{l}\text { Representações } \\
\text { sociais do cuidado } \\
\text { prestado aos paci- } \\
\text { entes soropositivos } \\
\text { ao HIV }\end{array}$ & $\begin{array}{l}\text { Pesquisa } \\
\text { qualitativa }\end{array}$ & $\begin{array}{l}\text { As representações sociais dos enfermeiros apoiam-se em conhe- } \\
\text { cimentos científicos reificados onde o processo de afastamento } \\
\text { dos cuidados assistenciais diretos ao paciente fica cada vez mais } \\
\text { nítido, sendo esses substituídos pelos cuidados indiretos como o } \\
\text { gerenciamento em Enfermagem dos serviços de saúde. }\end{array}$ \\
\hline $\begin{array}{l}\text { 3. GOMES, An- } \\
\text { tônio Marcos } \\
\text { Tosoli; CA- } \\
\text { BRAL, Ivone } \\
\text { Evangelista. } \\
2010\end{array}$ & $\begin{array}{l}\text { Ocultamento e } \\
\text { silenciamento de } \\
\text { familiares no cui- } \\
\text { dado à criança em } \\
\text { terapia antirretro- } \\
\text { viral }\end{array}$ & $\begin{array}{l}\text { Estudo } \\
\text { qualitativo }\end{array}$ & $\begin{array}{l}\text { Observou-se que o ocultamento e o silenciamento adotados por } \\
\text { familiares no cuidado à criança com HIV precisam ser abordados } \\
\text { durante o processo de cuidado ofertado por enfermeiros, sendo a } \\
\text { educação em saúde uma ferramenta importante para desmistificar } \\
\text { essa situação. O diálogo e a troca de saberes entre o profissional, a } \\
\text { família e a criança são indispensáveis ao processo educativo em } \\
\text { saúde. }\end{array}$ \\
\hline $\begin{array}{l}\text { 4. } \quad \text { BRASILEI- } \\
\text { RO, Marislei } \\
\text { Espíndula; CU- } \\
\text { NHA, Luiz Car- } \\
\text { los, } 2011 .\end{array}$ & $\begin{array}{l}\text { Diagnósticos de } \\
\text { enfermagem em } \\
\text { pessoas acometi- } \\
\text { das pela síndrome } \\
\text { da imunodeficiên- } \\
\text { cia adquirida em } \\
\text { terapia antirretro- } \\
\text { viral }\end{array}$ & $\begin{array}{l}\text { Descritivo- } \\
\text { explorató- } \\
\text { rio, de } \\
\text { abordagem } \\
\text { quantitativa }\end{array}$ & $\begin{array}{l}\text { O estudo comprova a importância do enfermeiro na área ambula- } \\
\text { torial, pois um diagnóstico de Enfermagem bem elaborado para } \\
\text { pessoas que são acometidas pela AIDS irá traçar um plano de } \\
\text { cuidados bem mais eficaz levando em consideração não só a do- } \\
\text { ença do paciente, mas, também, ele como um todo, nos seus as- } \\
\text { pectos biológico, fisiológico, psicológico, emocional e social, } \\
\text { melhorando a sua qualidade de vida durante, principalmente, o } \\
\text { processo de terapia antirretroviral. }\end{array}$ \\
\hline
\end{tabular}




\begin{tabular}{|c|c|c|c|}
\hline $\begin{array}{l}\text { 5. OLIVEIRA, } \\
\text { Roberta Mene- } \\
\text { ses; DA SILVA, } \\
\text { Lucilane Maria } \\
\text { Sales. } 2014\end{array}$ & $\begin{array}{l}\text { Dor crônica asso- } \\
\text { ciada à AIDS: } \\
\text { perspectiva de } \\
\text { enfermeiros e } \\
\text { médicos }\end{array}$ & $\begin{array}{l}\text { Estudo } \\
\text { qualitativo }\end{array}$ & $\begin{array}{l}\text { O enfermeiro, dentro da equipe multidisciplinar, exerce papel } \\
\text { importante para o alívio da dor do paciente por meio, principal- } \\
\text { mente, da administração de medicamentos para a analgesia, da } \\
\text { escuta ativa e do diálogo com o portador da síndrome diante da } \\
\text { dor crônica, mas se faz importante a adoção de instrumentos atua- } \\
\text { lizados para essa avaliação de forma humanizada e o mais indivi- } \\
\text { dualizada possível. }\end{array}$ \\
\hline $\begin{array}{l}\text { 6. COSTA, Ro- } \\
\text { manniny Hé- } \\
\text { villyn Silva; } \\
\text { SILVA, Richard- } \\
\text { son Augusto } \\
\text { Rosendo da; } \\
\text { MEDEIROS, } \\
\text { Soraya Maria de. } \\
2015 \text {. }\end{array}$ & $\begin{array}{l}\text { Cuidado de enfer- } \\
\text { magem diante da } \\
\text { prevenção } \text { da } \\
\text { transmissão verti- } \\
\text { cal do HIV }\end{array}$ & $\begin{array}{l}\text { Revisão } \\
\text { integrativa }\end{array}$ & $\begin{array}{l}\text { O enfermeiro apresenta-se como um profissional capaz de atuar } \\
\text { com as mais diversas possibilidades dentro da prevenção da } \\
\text { transmissão vertical do HIV, porém, é necessário que se abando- } \\
\text { nem certos modelos e práticas biomédicos a fim de superar alguns } \\
\text { paradigmas que permeiam a assistência desse profissional. Dessa } \\
\text { forma, buscar abarcar os aspectos sociais, culturais, políticos e } \\
\text { econômicos das gestantes é trabalhar sob a ótica de uma aborda- } \\
\text { gem centrada na pessoa empoderando-a e construindo, junto a ela, } \\
\text { seu plano de cuidados. }\end{array}$ \\
\hline $\begin{array}{l}\text { 7.LANGENDOR } \\
\text { F, Tassiane Fer- } \\
\text { reira et al. } 2015\end{array}$ & $\begin{array}{l}\text { Cotidiano do ser- } \\
\text { casal: significados } \\
\text { da profilaxia da } \\
\text { transmissão verti- } \\
\text { cal do HIV e pos- } \\
\text { sibilidades assis- } \\
\text { tenciais }\end{array}$ & Qualitativa & $\begin{array}{l}\text { Diante do contexto, enfermeiros que lidam diretamente com ca- } \\
\text { sais que vivenciam os cuidados com a profilaxia da transmissão } \\
\text { vertical do HIV mostram-se importantes no desenvolvimento de } \\
\text { um planejamento assistencial onde o reconhecimento das necessi- } \\
\text { dades dos pacientes e a junção às possibilidades terapêuticas de- } \\
\text { vem ser levados em consideração, por meio de uma escuta empá- } \\
\text { tica e autêntica, gerando um cuidado de Enfermagem de qualidade } \\
\text { para os indivíduos em seu caráter individual e no coletivo- } \\
\text { familiar. }\end{array}$ \\
\hline $\begin{array}{l}\text { 8. KOERICH, } \\
\text { Cintia et al. } \\
2015 \text {. }\end{array}$ & $\begin{array}{l}\text { Gestão do cuidado } \\
\text { de enfermagem ao } \\
\text { adolescente que } \\
\text { viver com } \\
\text { HIV/AIDS }\end{array}$ & $\begin{array}{l}\text { Estudo } \\
\text { qualitativo, } \\
\text { exploratório } \\
\text { e descritivo }\end{array}$ & $\begin{array}{l}\text { O estudo revela a importância de um maior envolvimento do en- } \\
\text { fermeiro no processo de acompanhamento e transição com a par- } \\
\text { ticipação ativa no planejamento, gestão e execução das ações } \\
\text { dentro das suas competências. }\end{array}$ \\
\hline $\begin{array}{l}\text { 9. COSTA, } \\
\text { Aline Mello } \\
\text { Salvaya da et al. } \\
2015 \text {. }\end{array}$ & $\begin{array}{l}\text { Cuidado de enfer- } \\
\text { magem às puérpe- } \\
\text { ras soropositivas } \\
\text { para o HIV diante } \\
\text { da impossibilidade } \\
\text { de amamentação } \\
\text { natural }\end{array}$ & $\begin{array}{l}\text { Pesquisa } \\
\text { descritiva, } \\
\text { explorató- } \\
\text { ria, de abor- } \\
\text { dagem qua- } \\
\text { litativa }\end{array}$ & $\begin{array}{l}\text { As enfermeiras devem ter, como base, a importância da orienta- } \\
\text { ção imediata sobre a não amamentação às gestantes em trabalho } \\
\text { de parto/parto que desconheciam ser soropositivas para o HIV e, } \\
\text { com isso, venham a oferecer um cuidado contínuo e poder passar } \\
\text { as informações com respeito desde o pré-natal. }\end{array}$ \\
\hline
\end{tabular}

Fonte: Dados da pesquisa. Senhor do Bonfim, 2018.

\section{DISCUSSÃO}

O conteúdo dos artigos pesquisados permitiu uma visão mais ampliada do cuidado pela enfermeira a um paciente portador de HIV/AIDS. Os estudos destacam a assistência prestada pela equipe de Enfermagem ao portador de HIV/AIDS, sendo importante tanto em ambiente hospitalar, como na atenção básica e outros serviços de referência em cuidados às pessoas convivendo com o HIV. Destacase, ainda, a participação da enfermeira como profissional responsável pela supervisão de toda a equipe de Enfermagem.

Para a melhor compreensão sobre a atuação da enfermeira no cuidado à pessoa vivendo com o HIV, os achados da pesquisa foram divididos em áreas pautadas na Assistência de Enfermagem, Gestão/Gerenciamento em Enfermagem e Educação em Saúde.

\section{Assistência de Enfermagem direta ao paciente}

Para Gomes e Cabral (2009), a enfermeira exerce um papel essencial diante do cuidado com pacientes portadores do HIV. Essa assistência se faz presente de forma direta quando, em seu estudo, os autores demonstraram a participação da profissional no âmbito da administração de medicamentos, uma vez que a terapia antirretroviral é indispensável para o controle do vírus e a manutenção da vida do portador.

Souza e Silva (2013) afirmaram que a Enfermagem é parte importante na equipe multiprofissional, por 
ter maior contato com o paciente, prestando atendimento terapêutico, educativo e apoio psicossocial, além de promover intervenções com maior eficácia analgésica e de aprimorar o atendimento interdisciplinar à dor para a sua melhor avaliação e tratamento.

Brasileiro e Cunha (2011), ao abordar os aspectos técnico-científicos, demostraram a importância da enfermeira por meio do uso da Sistematização da Assistência de Enfermagem (SAE), levando em consideração que um diagnóstico de Enfermagem bem traçado irá atender, de forma satisfatória, o paciente e sua família e trará uma abordagem centrada no ser humano e não resumidamente em sua doença.

Gomes et al. (2012), em pesquisa sobre a face singular do cuidado familiar à criança portadora do vírus HIV/AIDS, observaram que o ocultamento e o silenciamento do diagnóstico fazem parte do cotidiano de familiares e são encarados como um mecanismo de defesa com o intuito de proteção contra o preconceito e o isolamento social. Nesse sentido, o cuidado em Enfermagem visa a habilitar a pessoa para ser protagonista de sua vida e tem como objetivo instrumentalizá-la para escolhas responsáveis.

Assim, a enfermeira deve fornecer apoio e assessoramento adequados a familiares e a todos os que cuidam de crianças com HIV/AIDS, com a finalidade de oferecer resposta às suas dúvidas e temores, fornecendo informações pertinentes sobre $\mathrm{O}$ HIV/AIDS às pessoas do círculo social dessas famílias.

Diante dos estudos revisados, observou-se que a revelação do diagnóstico de HIV à criança soropositiva está cercada por diversas questões sociais, afetivas, culturais, éticas, morais e legais, sendo que o preconceito e o estigma ainda vivenciados pelas pessoas convivendo com o HIV é o maior fator influenciador nesse processo. Para tanto, a enfermeira é a pessoa capacitada e autônoma para oferecer cuidados e intervenções aos pacientes dando-lhes o conforto satisfatório por meio do reconhecimento do leque de possibilidades para lidar com situações delicadas.

Nos estudos de Costa, Silva e Medeiros (2015), nota-se que o cuidado de Enfermagem diante da prevenção da transmissão vertical evoluiu bastante, principalmente, devido aos avanços do Sistema Único de Saúde, porém, ainda se tem muito a melhorar. Entretanto, para que isso aconteça, segundo as autoras, é necessário um olhar mais amplo e crítico por parte dos estudantes de Enfermagem desde a sua base de formação, até o campo de trabalho para que se tenha maior agilidade e qualidade no cuidado de Enfermagem à criança e à família.

Langendorf et al. (2015) destacaram a importância da enfermeira em traçar uma linha para o planejamento assistencial ao casal que vivencia o agravo com os cuidados profiláticos a fim de se evitar a transmissão vertical. Com isso, tem-se uma possibilidade de a enfermeira assistir e ser assistida, reconhecer as reais necessidades do casal, quais as suas possibilidades terapêuticas e de atenção à saúde buscando sempre um cuidado mais qualificado para toda a família.

Sadala e Marques (2006) revelaram que estão concentrados em centros de referência para HIV/AIDS profissionais com maior aptidão para lidar com o público e a epidemia, enquanto que, nos demais serviços de saúde de assistência psicoterapêutica e social, os profissionais padecem mais pela falta de conhecimento específico na área. Portanto, a atualização da enfermeira em qualquer nível ou tipo de serviço em HIV/AIDS é indispensável para a melhoria da assistência e da qualidade de vida dos pacientes.

\section{O gerenciamento de Enferma- gem/gestão dos serviços e cuidados indiretos de saúde à pessoa convi- vendo com o HIV}

Macêdo et al. (2016) apresentaram, em seus resultados, uma amostra substancial da importância do papel da enfermeira na gestão dos serviços de saúde onde, por meio desta, tornase possível todo o desdobramento dos cuidados multiprofissionais às pessoas convivendo com o HIV. Entretanto, os mesmos chamam a atenção para a necessidade de uma maior aproximação da assistência direta ao paciente por parte dessa profissional.

De acordo com Formozo e Oliveira (2010), há um evidenciamento da preocupação que as enfermeiras possuem com as questões burocráticas do serviço de atendimento aos pacientes soropositivos para o HIV surtindo um efeito de afastamento dessa profissional de saúde dos cuidados diretos ao paciente e deixando-os a cargo de técnicos e auxiliares de Enfermagem apenas.

Araújo, Farias e Rodrigues (2012) afirmaram que a equipe de Enfermagem não realiza uma abordagem adequada para acolher o público de puérperas portadoras do HIV, uma vez que elas recebem a mesma forma de tratamento que as demais, não se considerando, portanto, suas peculiaridades.

Araújo, Signes e Zampier (2006) observaram que, nas unidades básicas de saúde da família, durante a entrega do resultado, não ocorreu um 
diálogo entre a enfermeira e a paciente, uma vez que as consultas se resumiam, na maioria das vezes, a um procedimento mecânico (preenchimento de cartão da gestante, alimentação de dados no sistema informatizado), atitudes que desfavoreceram, dessa forma, o vínculo e o acolhimento que devem ocorrer entre a profissional e a usuária.

Koerich et al. (2015), em estudo sobre a gestão do cuidado de Enfermagem ao adolescente que vive com HIV, demonstraram que um maior envolvimento, por parte da enfermeira, é de suma importância para o cuidado, por meio de uma participação ativa no planejamento, gestão e execução das ações, de forma que a integralidade seja o foco do atendimento a esse público. Isso, porém, não exime a responsabilidade da Enfermagem diante da integralidade do cuidado às demais pessoas que convivem com o vírus da AIDS.

3 Educação em Saúde como ferramenta de cuidado para a enfermeira que lida com pacientes convivendo com o HIV/AIDS e seus familiares

A educação em saúde é um elemento fundamental no cuidado prestado pela enfermeira em quaisquer áreas de atuação onde possa estar presente. Gomes e Cabral (2009) demonstraram a efetividade que esse instrumento de trabalho tem diante da assistência prestada às famílias cuidadoras de crianças portadoras do HIV.

Gomes e Cabral (2010), em estudo realizado sobre o ocultamento e o silenciamento de familiares no cuidado à criança em terapia antirretroviral, observaram que esse tema precisa ser abordado no processo de educação em saúde por enfermeiras que realizam suas intervenções no acompanhamento a essas famílias.

Poletto e Motta (2015) afirmaram que a enfermeira que atua em equipe multidisciplinar, como profissional habilitada para exercer essa função, apresenta essa característica devido à sua formação e qualificação para a educação em saúde. A atividade educativa aproxima o enfermeiro da criança e família possibilitando a expressão de sentimentos, pensamentos e emoções que se constituem fatores imprescindíveis na relação cuidadocuidador. Cria-se, assim, vínculo para que crianças e familiares sintam-se apoiados e confiantes para discutir abertamente o plano terapêutico livres de possíveis julgamentos.

Frente ao exposto, percebe-se que a educação em saúde é uma ferramenta que a equipe de Enfermagem pode utilizar para levar informações tanto à pessoa vivendo com HIV, quanto à família esclarecendo dúvidas que as mesmas possam ter e, com isso, ofertando um cuidado eficaz e humanizado.

Segundo Costa, Silva e Medeiros (2015), diante do acolhimento ofertado pela Enfermagem às gestantes soropositivas, no momento da admissão, o bem-estar experimentado tornase essencial para a saúde dessas mulheres. Desse modo, além da assistência prestada e dos protocolos utilizados no atendimento às mulheres que vivem com o HIV, as profissionais também devem aconselhá-las a respeito da suspensão da amamentação e do trabalho de parto natural por conta dos riscos de contaminação vertical.

Costa (2015) afirmou a importância da atuação da enfermeira prestando cuidados e orientações às puérperas soropositivas para o HIV tanto no âmbito do uso de técnicas inibido- ras da amamentação, como diante do uso de fármacos com o mesmo fim, sensibilizando-as sobre a importância de não amamentar sem, contudo, perder o vínculo com o seu bebê. Disse, ainda, que o momento da alimentação artificial deve ser aproveitado pela puérpera para criar uma aproximação com o seu filho. Constatou-se, assim, a importância da enfermeira no cuidado e na orientação de puérperas soropositivas para o HIV diante da possiblidade de contaminação durante a lactação tendo em vista que muitas mulheres desconhecem os riscos.

Reitera-se que, no tocante ao cuidado de Enfermagem na prevenção da transmissão vertical, ainda existem obstáculos a serem superados e, para isso, é necessário que haja uma junção de trabalho multiprofissional e atuação de gestores gerando uma assistência de qualidade e de liberdade no âmbito da atuação profissional e no empoderamento dos pacientes e suas famílias.

Ayres et al. (2009) ressaltaram que é preciso identificar os sentimentos com os profissionais de saúde para que se estabeleça um relacionamento verdadeiro e solidário com as pessoas que vivem com o HIV. Consideraram, ainda, a importância da busca pelo reconhecimento e pelo apoio que os profissionais necessitam para se tornarem cada vez mais aptos para lidar com a abordagem a esse público em questão.

As limitações do estudo devem-se à utilização de apenas duas bases de dados, apesar de suas importâncias e abrangências. Quanto aos pontos fortes, considera-se que a organização da análise em três categorias (Assistência de Enfermagem, Gestão/Gerenciamento em Enfermagem e Educação em Saúde) possibilitou um olhar mais acurado para a produção 
científica e revelou as dimensões da prática profissional para com a pessoa vivendo com o HIV.

\section{CONSIDERAÇÕES FINAIS}

De acordo com os estudos revisados, observou-se que a enfermeira está inserida no cuidado ao portador de HIV/AIDS sob diversas maneiras, dentre elas, o acolhimento e a orientação voltados à educação em saúde, à prevenção de doenças oportunistas, ao diagnóstico e a posteriores intervenções, além de apoio psicológico ao paciente e à família.

Fica evidente que a enfermeira, como um membro importante na equipe multidisciplinar, busca estabelecer um vínculo com o paciente no sentido de ofertar um cuidado eficiente ao usuário e à família. No entanto, os achados apresentam a existência de fragilidades em relação ao atendimento como algo que ainda persiste pelo fato de o HIV ser um agravo complexo e vivenciado em sua singularidade por cada indivíduo/família.

Em virtude dos fatos mencionados, é possível afirmar que a enfermeira, bem como a equipe de Enfermagem, é parte essencial no cuidado a pessoa que vive com HIV e, apresenta conhecimento sobre como atuar frente aos diversos públicos e faixas etárias afetados pelo agravo. A enfermeira, também, busca desmistificar o preconceito que ainda existe por parte da família e da sociedade apropriando-se de um cuidado que contemple o indivíduo na sua integralidade, apoiandose em atividades assistenciais, gerenciais e educativas.

\section{REFERÊNCIAS}

ARAÚJO, C. L. F.; SIGNES, A. F.; ZAMPIER, V. S. B. O cuidado à puérpera com HIV/AIDS no alojamento conjunto: a visão da equipe de enfermagem. Esc. Anna Nery Rev. enferm., v. 16, n. 1, p. 49-56, 2012. Disponível em:

$<$ http://www.scielo.br/pdf/ean/v16n1/v 16n1a07.pdf $>$. Acesso em: $06 \mathrm{dez}$. 2017.

ARAÚJO, M. A. L.; FARIAS, F. L. R.; RODRIGUES, A. V. B. Aconselhamento pós-teste anti-HIV: análise a luz de uma teoria humanística de Enfermagem. Esc Anna Nery Rev. enferm., v. 10, n. 3, p. 425-31, 2006.

Disponível em:

$<\mathrm{http}: / /$ www.scielo.br/pdf/ean/v10n3/v 10n3a10.pdf >. Acesso em: $04 \mathrm{dez}$. 2017.

AYRES, José Ricardo C. M. et al. Adolescentes e jovens vivendo com HIV/Aids: cuidado e promoção à saúde no cotidiano da equipe multiprofissional. In: Cuidado: trabalho e interação nas práticas de saúde. 2009. p. 233-282. Disponível em: <

http://bvsms.saude.gov.br/bvs/publicac oes/11ManualECI_final.pdf $>$. Acesso em: 05 dez. 2017.

\section{BRASILEIRO, M. E.; CUNHA, L.C.} Diagnósticos de enfermagem em pessoas acometidas pela síndrome da imunodeficiência adquirida em terapia antirretroviral. Rev. enferm. UERJ, v. 19, n. 3, p. 392-396, 2011. Disponível em: <

http://www.facenf.uerj.br/v19n3/v19n 3a09.pdf >. Acesso em: 03 dez. 2017.

COSTA, A. M. S. et al. Cuidado de enfermagem às puérperas soropositivas para o HIV diante da impossibilidade de amamentação natural. Rev. pesqui. cuid. fundam. (Online), v. 7 , n. 2, p. 2310-2322, 2015. Disponível em: < http://bases.bireme.br/cgibin/wxislind.exe/iah/online/?IsisScript $=\mathrm{iah} / \mathrm{iah} . \mathrm{xis} \& \mathrm{src}=$ google $\&$ base $=\mathrm{BDE}$

NF\&lang $=p \&$ nextAction $=$ lnk\&exprSe arch $=26823 \&$ indexSearch $=$ ID $>$.

Acesso em: 08 dez. 2017.

COSTA, R. H. S.; SILVA, R. A. R.; MEDEIROS, S. M. Cuidado de enfermagem diante da prevenção da transmissão vertical do HIV. Rev. pesqui. cuid. fundam. (Online), p. 21472158, 2015. Disponível em: < http://saudepublica.bvs.br/pesquisa/res ource/pt/bde-26727 >. Acesso em: 08 dez. 2017.

CUNHA, G. H. et al. Práticas de higiene para pacientes com

HIV/AIDS. Revista Gaúcha de Enfermagem, Porto Alegre, v. 35, n. 3 , p.137-144, set. 2014. Disponível em: <http://seer.ufrgs.br/RevistaGauchade Enfermagem/article/view/44928/31530>. Acesso em: 20 set. 2018.

FORMOZO, G. A.; OLIVEIRA, D. C. Representações sociais do cuidado prestado aos pacientes soropositivos ao HIV. Rev. bras. enferm., Brasília, v. 63, n. 2, p. 230-237, 2010. Disponível em:

$<$ http://www.scielo.br/scielo.php?pid= S0034-

$71672010000200010 \&$ script=sci_abstr act \&tlng=pt $>$. Acesso em: $11 \mathrm{dez}$. 2017.

GOMES, A. M. T.; CABRAL, I. E. O cuidado medicamentoso à criança com HIV: desafios e dilemas de familiares cuidadores. Rev. bras. enferm., Brasília, v. 62 , n. 2, p. 252-257, 2009. Disponível em: 
<http://www.scielo.br/scielo.php?pid= S0034-

71672009000200013\&script=sci_abstr act\&tlng=pt $>$. Acesso em: $13 \mathrm{dez}$. 2017.

GOMES, A. M. T.; CABRAL, I. E. Ocultamento e silenciamento familiares no cuidado à criança em terapia antiretroviral. Rev. bras. en-

ferm., Brasília, v. 63, n. 5, p. 719-726, 2010. Disponível em: <

http://www.scielo.br/pdf/reben/v63n5/ 05.pdf >. Acesso em: 10 dez. 2017.

GOMES, G. C. et al. Face singular do cuidado familiar à criança portadora do vírus HIV/AIDS. Acta paul. en-

ferm., São Paulo, v. 25, n. 5, p. 749-

754, 2012. Disponível em: <

http://www.scielo.br/scielo.php?pid=S 0103 -

21002012000500016\&script=sci_abstr act\&tlng $=\mathrm{pt}>$. Acesso em: $09 \mathrm{dez}$. 2017.

KOERICH, C. et al. Gestão do cuidado de enfermagem ao adolescente que vive com HIV/AIDS. Esc. Anna Nery Rev. Enferm, v. 19, n. 1, p. 115-123, 2015. Disponível em: < http://www.scielo.br/pdf/ean/v19n1/14 14-8145-ean-19-01-0115.pdf >. Acesso em: 16 dez. 2017.

LANGENDORF, T. F. et al. Cotidiano do ser-casal: significados da profilaxia da transmissão vertical do HIV e possibilidades assistenciais. Esc. Anna

Nery Rev. Enferm, p. 259-264, 2015. Disponível em: <

http://www.scielo.br/scielo.php?pid=S 1414-

$81452015000200259 \&$ script=sci_abstr act\&tlng=pt > . Acesso em: $14 \mathrm{dez}$. 2017.
MACÊDO, S. M. et al. Cuidado de enfermagem em Serviço Ambulatorial Especializado em HIV/Aids. Revista Brasileira de Enfermagem, v. 69, n. 3, p. 515-521, 2016. Disponível em: < http://www.scielo.br/pdf/reben/v69n3/ 0034-7167-reben-69-03-0515.pdf >.

Acesso em: 07 dez. 2017.

MONTEZELLI, J. H.; PERES, A. M.; BERNARDINO, E. Demandas institucionais e demandas do cuidado no gerenciamento de enfermeiros em um pronto socorro. Rev. bras. en-

ferm., Brasília, v. 64, n. 2, p. 348-354, 2011. Disponível em: <

http://www.scielo.br/scielo.php?script =sci_arttext\&pid=S0034-

71672011000200020 >. Acesso em: 12 dez. 2017.

OLIVEIRA, R. M.; SILVA, L. M. S. Dor crônica associada a AIDS: perspectiva de enfermeiros e médicos. Rev. bras. enferm, v. 67, n. 1, p. 54-61, 2014. Disponível em: < http://www.scielo.br/scielo.php?script $=$ sci_arttext\&pid=S0034-

71672014000100054 >. Acesso em: 13 dez. 2017.

POLETTO, P. M. B.; MOTTA, M. G.

C. Educação em saúde na sala de espera: cuidados e ações à criança que vive com HIV/aids. Esc. Anna Nery, Rio de Janeiro, v. 19, n. 4, p. 641-647, 2015. Disponível em: < http://www.scielo.br/scielo.php?pid=S 1414-

$81452015000400641 \&$ script=sci_abstr act\&tlng=pt $>$. Acesso em: $07 \mathrm{dez}$. 2017

ROCHA, G. S. A. et al. Nursing care of hiv-positive patients: considerations in the light of phenomenology. Reme: Revista Mineira de Enfermagem, [s.l.], v. 19, n. 2, p.262-265, 2015. Disponível em:

$<$ http://reme.org.br/artigo/detalhes/102 0>. Acesso em: 20 set. 2018.

SADALA, M. L. A.; MARQUES, S. A. Vinte anos de assistência a pessoas vivendo com HIV/AIDS no Brasil: a perspectiva de profissionais da saúde. Cad. Saúde Pública, Rio de Janeiro, v. 22, n. 11, p. 2369-2378,

2006. Disponível em: < http://www.scielo.br/scielo.php?pid=S 0102-

311X2006001100011\&script=sci_abst ract\&tlng=pt $>$. Acesso em: $11 \mathrm{dez}$. 2017.

SILVA, E. L.; MENEZES, E. M. Metodologia da pesquisa e elaboração de dissertação. 4. ed. Florianópolis: UFSC, 2005. 138 p. Disponível em: $<$ http://www.portaldeconhecimentos.or g.br/index.php/por/content/view/full/1 0232>. Acessado em: 09 dez. 2017.

SMELTZER, Suzanne C; Bare, Brenda G. Brunner/Suddarth. Tratado de enfermagem médico cirúrgica. 11. ed. Rio de Janeiro: Guanabara Koogan, 2008.

SOUSA, C. S. O.; SILVA, A. L. O cuidado a pessoas com HIV/aids na perspectiva de profissionais de saúde.

Rev. esc. enferm., USP, São Paulo, v. 47, n. 4, p. 907-914, 2013. Disponível em:

$<$ http://www.scielo.br/scielo.php?pid= S0080-

62342013000400907\&script=sci_abstr act\&tlng=pt $>$. Acesso em: $06 \mathrm{dez}$. 2017.

SUTO, C. S. S.; OLIVEIRA, J. F.; PAIVA, M. S. Social Representations of health care professionals on Ac- 
quired Immune Deficiency Syndrome. Rev. bras. enferm., [s.1.], v. 71, n. 4, p.1934-1939, ago. 2018. Disponível em:

$<$ http://www.scielo.br/pdf/reben/v71n4 /pt_0034-7167-reben-71-04-

1934.pdf>. Acesso em: 20 set. 2018.

TONNERA, L. C. J.; MEIRELLES, B. H. S. Potencialidades e fragilidades da rede de cuidado da pessoa com

HIV/AIDS. Rev. bras. en-

ferm., Brasília, v. 68 , n. 3, p. 438-

444, 2015. Disponível em: <

http://www.scielo.br/scielo.php?pid=S

0034-

71672015000300438\&script=sci_abstr act\&tlng $=\mathrm{pt}>$. Acesso em: $13 \mathrm{dez}$.

2017.

VALE, E. G.; PAGLIUCA, L. M. F. Construção de um conceito de cuidado de enfermagem: contribuição para o ensino de graduação. Rev. bras. enferm., [s.l.], v. 64, n. 1, p.106-113, fev. 2011. Disponível em: <http://www.scielo.br/pdf/reben/v64n1 /v64n1a16.pdf $>$. Acesso em: 20 set. 2018.

VOSGERAU, D. S. R.; ROMANOWSKI, J. P. Estudos de revisão implicações conceituais e metodológicas.

Rev. Diálogo Educ. Curitiba, v. 14, n. 41, p. 165-189, 2014. Disponível em: $<$ https://periodicos.pucpr.br/index.php/d ialogoeducacional/article/view/2317>. Acesso em: 10 dez. 2017. 